\title{
Respiratory Syncytial Virus Infection Reversed Anti-Asthma Effect of Neonatal Bacillus Calmette-Guerin Vaccination in BALB/c Mice
}

\author{
RUI LI, XIQIANG YANG, LIJIA WANG, AND ENMEI LIU \\ Department of Clinical Immunology [R.L., X.Y., L.W.], Division of Respiratory Disorders [E.L.], Children's Hospital, Chongqing \\ University of Medical Sciences, Chongqing 400014, China
}

\begin{abstract}
Bacillus Calmette-Guerin (BCG) vaccination can protect animals from asthma, but the effect of BCG on childhood asthma prevention is controversial in humans. To verify the hypothesis that the BCG anti-asthma effect in childhood might be reversed by a respiratory virus infection, newborn BALB/c mice were divided into five groups. Control and ovalbumin (OVA) groups were mock vaccinated and mock infected. The BCG/OVA group was BCG vaccinated and mock infected. The respiratory syncytial virus (RSV)/ OVA group was mock vaccinated and RSV infected. The BCG/RSV/ OVA group was BCG vaccinated and RSV infected. Except for the control group, all groups underwent OVA sensitization and challenge. Airway hyperresponsiveness (AHR) was measured after challenge and cells in bronchoalveolar lavage fluid (BALF) were counted. Cytokines in BALF and serum OVA-specific IgE were detected by ELISA and inflammatory characteristics of lung sections were scored. Mice with neonatal BCG vaccination (BCG/OVA group) were significantly protected from BALF eosinophilia, AHR to methacholine, peribronchiolitis, alveolitis, and peribronchial eosinophilia in comparison with the OVA, RSV/OVA, and BCG/RSV/ OVA groups. AHR in the OVA group was greater than in the BCG/OVA group but lower than in the RSV/OVA and BCG/RSV/ OVA groups. No significant differences in BALF eosinophilia, AHR, and lung inflammation were found between the RSV/OVA and BCG/RSV/OVA groups. The impact of BCG vaccination on antiasthma in mice was not dependent on interferon- $\gamma$, IL-4, and IL-10 levels. The results suggested that RSV infection can reverse the anti-asthma effect of neonatal BCG vaccination in BALB/c mice. (Pediatr Res 59: 210-215, 2006)
\end{abstract}

A sthma is a common chronic allergic disease in children. The prevalence of asthma has increased dramatically in recent decades, affecting more than $30 \%$ of the population, especially in developed countries (1). The reason for this increasing prevalence of asthma has not been elucidated. The "hygiene hypothesis" suggests that the improved hygiene in industrialized countries and the use of vaccines and antibiotics has caused the decline of many infectious diseases that would

Received January 31, 2005; accepted August 5, 2005.

Correspondence: Enmei Liu, M.D., Ph.D., Division of Respiratory Disorders, Children's Hospital, Chongqing University of Medical Sciences, Chongqing 400014, China; e-mail: emliu186@hotmail.com

This project was supported by grants from the National Natural Scientific Foundation of China (NSFC 30240008 and 30300321).

DOI: $10.1203 / 01 . p d r .0000196368 .08210 .5 c$ normally stimulate the immune system in some way that mitigates against asthma $(2,3)$.

According to the hygiene hypothesis, infections with some pathogens, for example Mycobacteria tuberculosis, in early childhood may be important for protection from asthma. In a survey among 867 Japanese children, all immunized with BCG, skin test reactivity to tuberculin was shown to inversely correlate with the likelihood of having asthma (4). Multiple studies in animal models have demonstrated that treatments with either live or dead mycobacteria are capable of inhibiting allergen-induced lung inflammatory responses (5-10). It has been shown that BCG can reduce the formation of specific $\mathrm{IgE}$, eosinophilia, and bronchial hyper-responsiveness induced by allergen with an increase in interferon (IFN)- $\gamma$ production (5-7). Similarly, heat-killed BCG, Mycobacterium vaccae, and purified protein derivative from $M$. tuberculosis have all been shown to suppress allergic and asthma-like responses in mice $(8-10)$. However, it is controversial whether BCG vaccination decreases asthma prevalence in humans. Some studies support the role of BCG in inhibiting asthma and allergy development $(4,11,12)$, whereas other studies do not $(13,14)$. Why the anti-asthma of BCG is different between animals and humans has not been elucidated.

A positive association between infection with some respiratory viruses and asthma has been recognized for decades. Respiratory virus infection inhibits induction of tolerance and increases sensitization to inhaled allergens resulting in increased airway inflammation and airway hyper-responsiveness (15). Severe infantile RSV infection appears to increase the risk of recurrent wheezing and developing asthma (16), although this may disappear by the age of 13 y (17).

BCG is given to every neonate in mainland China. However, during the first or second year of life, almost all children are infected with RSV (18). We proposed a hypothesis that the role of BCG vaccination as protection from asthma in humans

Abbreviations: AHR, airway hyperresponsiveness; BAL, bronchoalveolar lavage; BALF, bronchoalveolar lavage fluid; BCG, Bacillus CalmetteGuerin; OVA, ovalbumin; RSV, respiratory syncytial virus 
might be reversed by respiratory virus infection. In this study, we investigated the combined effect of neonatal Bacillus Calmette-Guerin vaccination and RSV infection on asthma development in BALB/c mice.

\section{MATERIALS AND METHODS}

Mice. BALB/c mice, free of specific pathogens, housed in individual filtered cages, were maintained on OVA-free diets. Cages, bedding, food, and water were sterilized before use. Room temperature was maintained at $27^{\circ} \mathrm{C}$, and a 12-h on, 12-h off light cycle was provided. Pregnant mice went into labor at $\mathrm{d} 20$ of pregnancy and newborn mice were raised and maintained in the same conditions. This study was approved by the Institutional Animal Care and Research Advisory Committee at the Chongqing University of Medical Sciences. All experimental animals were used in accordance with the guidelines issued by the Chinese Council on Animal Care.

Cell and virus. HEp- 2 cells were maintained in Eagle's minimal essential media (EMEM) supplemented with glutamine, fungiazone, gentamicin, penicillin G, and $10 \%$ fetal bovine serum (10\% EMEM). Human RSV A2 strain was grown in HEp-2 cells and titrated by plaque assay. Master stock and working stock of RSV were prepared as described previously (19).

Study groups. Newborn mice were divided into five groups. Every group contained 14 mice, 8 for BAL and 6 for pulmonary resistance and histopathology. Control and OVA groups were mock vaccinated and mock infected. The BCG/OVA group was BCG vaccinated and mock infected. The RSV/ OVA group was mock vaccinated and RSV infected, and the BCG/RSV/OVA group was BCG vaccinated and RSV infected. The study protocol is outlined in Figure 1

BCG vaccination and $R S V$ infection. Newborn mice were immunized subcutaneously on the back with a 30-gauge needle from a tuberculin syringe with $20 \mu \mathrm{L}$ of BCG [ $1 \times 10^{5}$ colony-forming units $\left.(\mathrm{CFU})\right]$. Mock-vaccinated mice were injected with the same amount of BCG diluent in the same area. At 3 wk of age, mice were infected with RSV intranasally. Briefly, the mice were lightly anesthetized intraperitoneally with $0.3 \%$ pentobarbital sodium. When held upright with the neck fully extended, the mice readily inhaled a $50-\mu \mathrm{L}$ inoculum of stock virus $\left(10^{6}\right.$ plaque-forming units of RSV) placed into their nostrils with a micropipette. Infection was confirmed in a subset of mice by immunofluorescence detection of RSV antigen in cells from BALF $3 \mathrm{~d}$ postinfection. Mock-infected mice were inoculated intranasally with the same amount of HEp-2 cell culture supernatant at the same time point.

OVA sensitization and challenge. Except for the control group, mice from all groups were sensitized twice at 4 and $6 \mathrm{wk}$ of age as described by Oh $e t$ al. (20). Briefly, OVA (grade V, $500 \mu \mathrm{g} / \mathrm{mL}$ ) in PBS was mixed with equal volumes of $10 \%(\mathrm{wt} / \mathrm{vol}$ ) aluminum potassium sulfate (alum; Sigma Chemical Co., St. Louis, MO) in distilled water and incubated for $60 \mathrm{~min}$ at room temperature after adjustment to $\mathrm{pH} 6.5$ using $10 \mathrm{~N} \mathrm{NaOH}$. After centrifugation at $750 \times g$ for $5 \mathrm{~min}$, the OVA/alum pellet was resuspended to the original volume in distilled water. Mice received an intraperitoneal injection of $100 \mu \mathrm{g}$ OVA ( $0.2 \mathrm{~mL}$ of $500 \mu \mathrm{g} / \mathrm{mL}$ in normal saline) complexed with alum. At $7 \mathrm{wk}$ of age, all OVA-sensitized mice were challenged with aerosols of 5\% OVA (grade II) diluted in PBS for $30 \mathrm{~min}$ each day on 10 consecutive days. Mice from control group received a mock sensitization with intraperitoneal alum alone and a mock challenge with aerosol PBS at the corresponding time.

BAL and cell counting. Mice were anesthetized with urethane $(15 \mathrm{mg} / 10$ g body weight intraperitoneally) $24 \mathrm{~h}$ after the last OVA challenge, and the abdominal cavity was opened. Blood samples for serum were collected from the vena cava. The tracheas were cannulated, and BAL was performed by two lavages with $0.5 \mathrm{~mL}$ ice-cold PBS. The total cell number in BALF was determined. The BAL was centrifuged and supernatant used to test for cytokine production and the cell pellet used to prepare slides for differential cell counting. Cytospin slides were fixed and stained with DiffQuik (Baxter

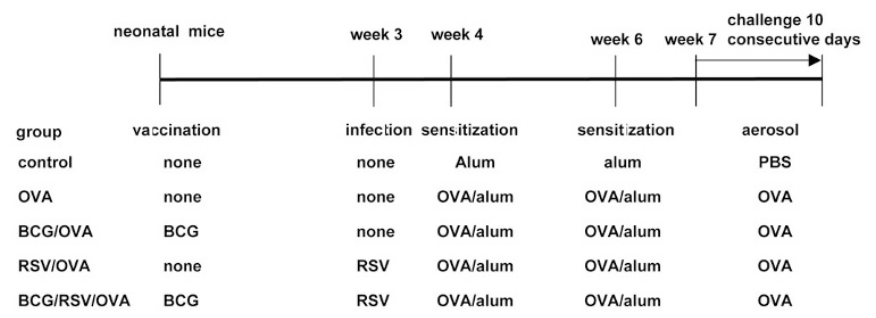

Figure 1. Time points of experimental protocol. Lung resistance of mice was measured and BAL performed $24 \mathrm{~h}$ after the last OVA challenge.
Healthcare Corp, Deerfield, Miami, FL) for leucocyte differential analysis, and the number of monocytes, lymphocytes, neutrophils, and eosinophils in a total of 200 cells were counted in each slide.

Cytokines analysis. Concentrations of cytokines in BALF were measured with commercial ELISA kits according to the manufacturer's instructions. Murine IFN- $\gamma$ and IL-10 ELISA kits were purchased from Tepnel Diaclone (Besancon Cedex, France) and IL-4 from Bender MedSystems (Vienna, Austria).

Anti-OVA-specific IgE levels in serum. Anti-OVA-specific IgE in the sera were measured by ELISA as done previously (21). Briefly, the microplate was coated with $100 \mu \mathrm{L}$ of OVA $(20 \mu \mathrm{g} / \mathrm{mL})$, mouse sera were incubated in the antigen-coated wells, and bound IgE was detected with a biotinylated antimouse IgE. Diluted avidin-alkaline phosphatase was added, the bound enzyme was detected with 3,3'5,5'-tetramethylbenzidine substrate, and the absorbance read at $450 \mathrm{~nm}$.

Methacholine challenge. Lung resistance of mice was measured with AniRes 2000 animal lung function analysis systems (Aerospace New Concept Software Co., Ltd., Beijing, China). Mice were anesthetized with intraperitoneal injection of $20 \%$ urethane $0.2 \mathrm{~mL} 24 \mathrm{~h}$ after the last OVA challenge, and the tracheostomy tube was placed. The mice were then placed in a whole-body plethysmography chamber and ventilated mechanically at a rate of 120 breaths per minute with a tidal volume of $10 \mathrm{~mL} / \mathrm{kg}$. Acetyl- $\beta$ methacholine (Sigma Chemical Co.) was dissolved into 0.2, 0.4, 0.8, 1.6, and $3.2 \mathrm{~g} / \mathrm{L}$ in PBS and an aerosol challenge at each dose was administered via a nebulizer. After each dose of challenge, airway pressure and lung volume changes were recorded, and pulmonary resistance was calculated using provided software program.

Histopathology. Formalin-fixed lungs were embedded in paraffin, sectioned in $6-\mu \mathrm{m}$ thick slices, and stained with hematoxylin and eosin for routine histology. In a blinded fashion, an experienced histologist examined the slides for peribronchiolitis, perivasculitis, alveolitis, and eosinophilia. Lung lesions were scored semi-quantitatively as described by other researchers $(22,23)$. Severity of inflammation was evaluated by assigning a value of 0 for no inflammation, 1 for mild inflammation, 2 for moderate inflammation, and 3 for severe inflammation (Fig. 2). Eosinophilia was determined by counting the number of eosinophils within the inflamed peribronchial region and expressing this as a percentage.

Statistical analysis. Results were shown as mean \pm SD. Statistical analysis was performed with the statistical software package SigmaStat (SPSS Inc., Chicago, IL). All assays were compared using ANOVA followed by least squares difference- $t$ analysis. Differences were considered statistically significant when the $p$ value was $<0.05$.

\section{RESULTS}

Cellular composition of the lung inflammatory responses. In comparison with epithelial cells, which constituted the majority of BAL cells in the control group, lymphocytes were the major inflammatory cells found in BALF from other groups that underwent OVA sensitization and challenge. The number of total cells (Fig. 3A), lymphocytes (Fig. 3B), monocytes, neutrophils, and eosinophils (Fig. $3 C$ ) in the BALF of OVA, BCG/OVA, RSV/OVA, and BCG/RSV/OVA groups were all significantly greater than in control group $(p<0.01)$. The number of total cells and eosinophils in the BCG/OVA group was significantly lower than in the OVA, RSV/OVA, and BCG/RSV/OVA groups, with the lymphocyte number significantly lower than in the OVA and BCG/RSV/OVA groups. However, there was no difference in the number of monocytes and neutrophils between the four groups (data not shown).

Cytokine production in BALF. The levels of IFN- $\gamma, \mathrm{IL}-4$, and IL-10 in BALF were assayed by ELISA, which represent Th1, Th2, and regulatory $\mathrm{T}$ cell response, respectively. As showed in Figure 4, all OVA-sensitized/challenged groups (OVA, BCG/OVA, RSV/OVA, and BCG/RSV/OVA groups) had significantly lower IFN- $\gamma$ and higher IL-4 level than the control, but there was no significant difference among these four groups. The ratio of IFN- $\gamma / \mathrm{IL}-4$ in all OVA-sensitized/ 


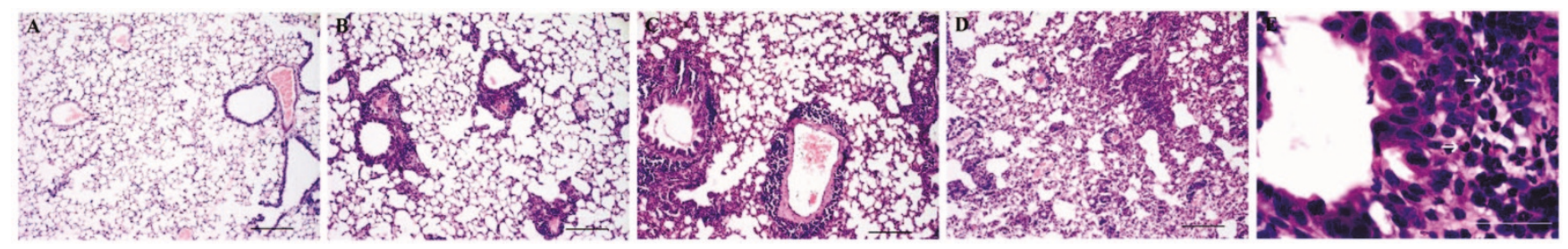

Figure 2. Representative hematoxylin and eosin-stained murine lung sections. Shown are representative sections for peribronchial inflammation for grade 0 (no inflammation) $(A)$; grade 1 (mild inflammation) $(B)$; grade 2 (moderate inflammation) $(C)$; grade 3 (severe inflammation) $(D)$; and peribronchial eosinophils (arrow) (E). Magnification is $\times 100$ and scale bar $=200 \mu \mathrm{m}$ for $A-D$; magnification is $\times 1000$ and scale bar $=0.5 \mu \mathrm{m}$ for $E$.

challenged groups was significantly lower than in control. There was no significant difference in IL-10 level among groups.

Serum OVA-specific IgE. As shown in Figure 5, OVAsensitized/challenged mice (OVA, BCG/OVA, RSV/OVA, and BCG/RSV/OVA groups) showed significantly higher serum OVA-specific IgE titers than control mice. However, there were not significant differences among all of the OVAsensitized or -challenged groups. The results showed that BCG vaccination, RSV infection, or their combination had no influence upon serum OVA-specific IgE titers caused by OVA immunization.

Airway reactivity to methacholine. Mice were challenged with aerosolized methacholine to measure AHR. There were no significant differences in baseline airway resistance among the five groups (Fig. 6). The airway resistance in the OVA, BCG/OVA, RSV/OVA, and BCG/RSV/OVA groups was obviously increased in a concentration-dependent manner by methacholine inhalation whereas only a slight increase could be detected in the control group. RSV/OVA and BCG/RSV/ OVA groups had significantly greater airway resistance than other groups, which were, in order of increasing severity, as follows: OVA group, BCG/OVA group, and control group, but there was no difference between the RSV/OVA and BCG/ RSV/OVA groups. Interestingly, RSV infection reversed the effect of BCG because BCG/RSV/OVA group showed significantly greater AHR than the OVA and BCG/OVA groups.

Histologic changes. The inflammatory characteristics caused by OVA sensitization/challenge are shown in Figure 7.

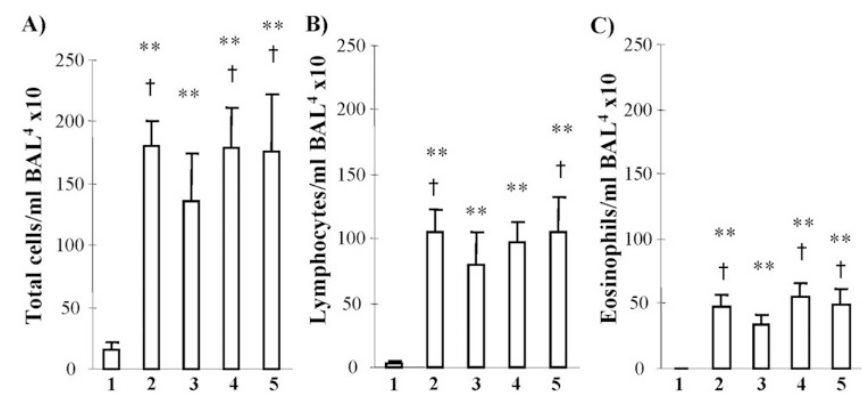

Figure 3. Composition of cell counts from BALF. Eight mice in control (1), OVA (2), BCG/OVA (3), RSV/OVA (4), and BCG/RSV/OVA (5) groups were killed for BALF. ** $p<0.01$ as compared with control group; $\dagger p<0.05$ as compared with BCG/OVA group. The number of $(A)$ total cells and $(C)$ eosinophils in the BCG/OVA group was significantly lower than in the OVA, RSV/OVA, and BCG/RSV/OVA groups, with the $(B)$ lymphocyte number significantly lower than in the OVA and BCG/RSV/OVA groups. Results showed as mean $\pm \mathrm{SD}$.
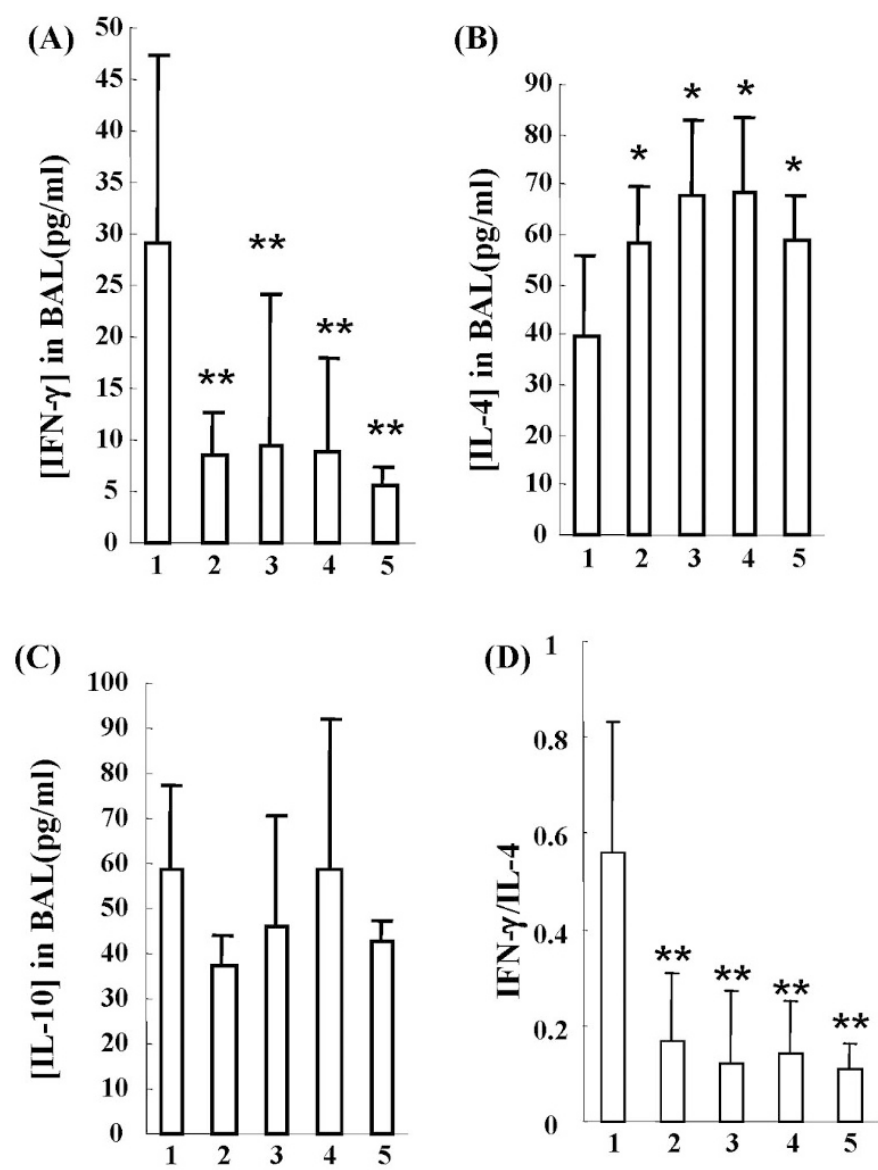

Figure 4. The absolute concentration of IFN- $\gamma$, IL-4, and IL-10 and the ratio of IFN $\gamma / \mathrm{IL}-4$ in BALF. Eight mice in control (1), OVA (2), BCG/OVA (4), RSV/OVA (4), and BCG/RSV/OVA (5) groups were killed for BALF. * $p<$ $0.05 ; * * p<0.01$ as compared with control group. Results showed as mean \pm SD.

Histologic scores of peribronchiolitis, perivasculitis, alveolitis, and peribronchial eosinophilia in all groups with OVA sensitization/challenge (OVA, BCG/OVA, RSV/OVA, and $\mathrm{BCG} / \mathrm{RSV} / \mathrm{OVA}$ groups) were significantly higher than that in the control group. Comparison among all groups with OVA sensitization/challenge showed that the BCG/OVA group had significantly milder peribronchiolitis, alveolitis, and peribronchial eosinophilia than other groups. However, there was no difference among these groups in terms of perivasculitis.

\section{DISCUSSION}

The increased prevalence of asthma over the past decades has become a major public health issue for the developed 


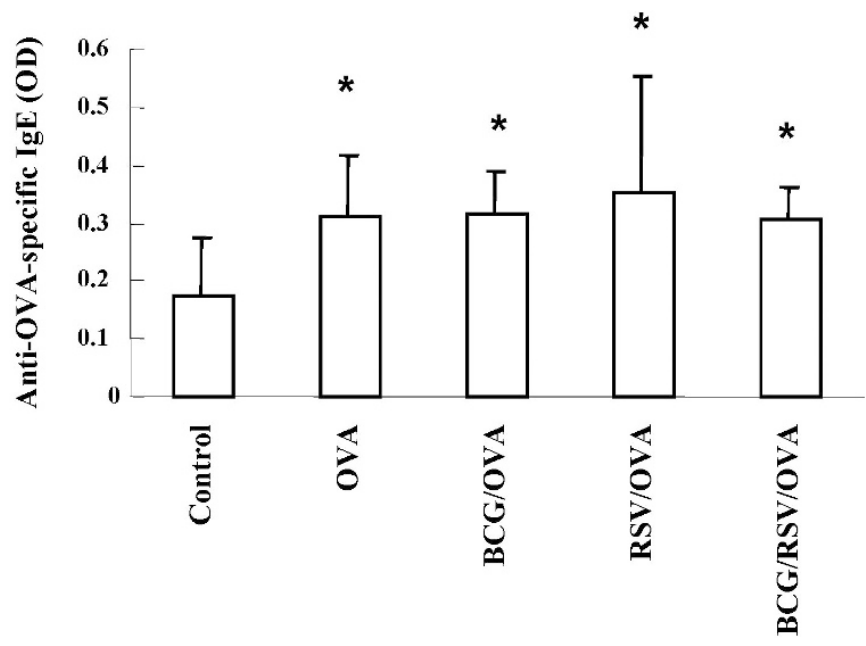

Figure 5. Serum OVA-specific IgE titers. Sera of eight mice in each group were measured by ELISA. * $p<0.05$ as compared with control group. Results showed as mean $\pm \mathrm{SD}$.

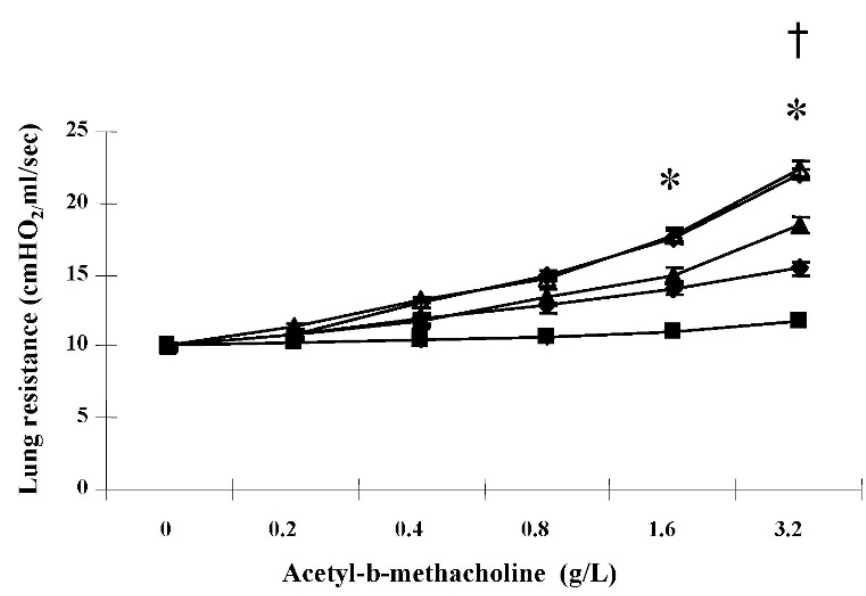

Figure 6. Result of methacholine challenge. $n=6$ for Control (ם), BCG/ OVA $(\diamond)$ BCG/RSV/OVA $(\diamond)$, OVA $(\boldsymbol{\Delta})$, and RSV/OVA $(\triangle)$ groups. $* p<$ $0.05 \mathrm{RSV} / \mathrm{OVA}$ and BCG/RSV/OVA group compared with other groups. $\dagger p$ $<0.05$ OVA group compared with BCG/OVA group. RSV/OVA and BCG/ RSV/OVA groups had significant greater airway resistance than other groups, which were, in order, as follows: OVA group, BCG/OVA group, and control group in severity of AHR, but there was no difference between the RSV/OVA and BCG/RSV/OVA groups.

countries. The "hygiene hypothesis" suggests that the increase in allergic diseases is caused by a cleaner environment and fewer childhood infections (24-28). Because a survey from Japan reported that skin test reactivity to tuberculin was shown to inversely correlate with the likelihood of having asthma (4), BCG has been studied as an anti-asthma vaccine in an attempt to verify the "hygiene hypothesis" in animals and in humans. Most of the animal studies focused on the impact of BCG on adult mice, whereas several studies used neonatal mice as a model to study heat-killed BCG by direct intranasal BCG administration $(29,30)$. In this study, we demonstrated that live BCG inoculated in neonatal mice by subcutaneous administration was capable of suppressing the development of OVA-induced airway eosinophilia, AHR, and histologic inflammation. However, neither inhibition of OVAspecific IgE nor the augmentation of Th1 response with
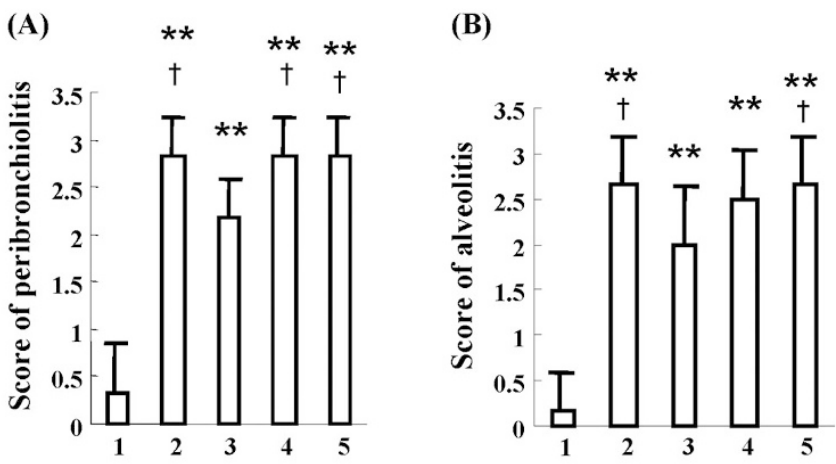

(C)
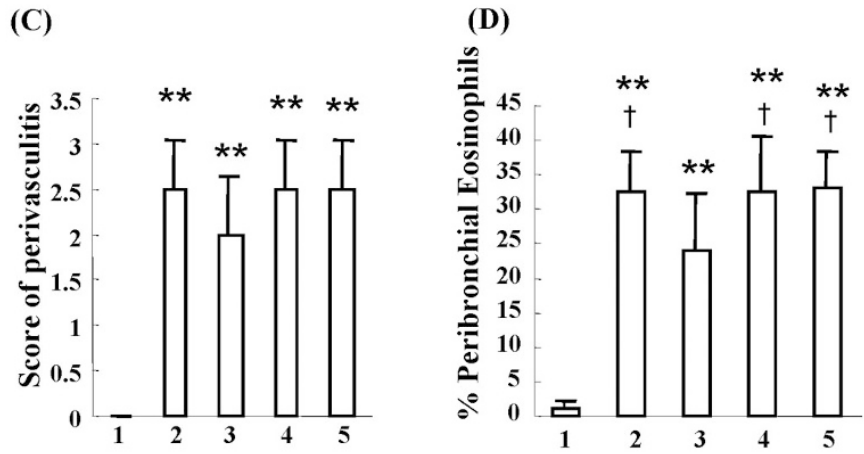

Figure 7. Histologic scores of pulmonary $(A)$ peribronchiolitis, $(B)$ alveolitis, $(C)$ perivasculitis, and $(D)$ percentage of peribronchial eosinophilia. $n=6$ for control (1), OVA (2), BCG/OVA (3), RSV/OVA (4), and BCG/RSV/OVA (5) groups. ${ }^{* *} p<0.01$ as compared with control group; $\dagger p<0.05$ as compared with BCG/OVA group. Results showed as mean \pm SD.

suppressed Th2 response was found in neonatal mice. The results suggested that the anti-asthma effect of neonatal BCG vaccination is not through the Th1/Th2 paradigm, but that other Th1/Th2-independent immunologic regulatory mechanisms might be more important.

It has been reported that Mycobacterium vaccae induces CD4 regulatory $\mathrm{T}$ cells inhibiting OVA-induced airway inflammation through IL-10 and transforming growth factor beta (TGF- $\beta$ ) production (31). Our previous study showed that BCG promoted cord blood monocyte-derived dendritic cells' maturation and induced higher levels of IL-10 and medium levels of IFN- $\gamma$ but little IL-4 production by cord-naïve CD $4^{+}$ $\mathrm{T}$ cells (32), and intraperitoneal $\mathrm{BCG}$ vaccination of neonatal mice could induce more $\mathrm{IL}-10^{+} \mathrm{CD} 3^{+}$cells in spleen, which might represent some regulatory $\mathrm{T}$ cells producing IL-10 (data not shown). Here we showed that IL-10 production in BALF from asthmatic mice (OVA group) was significantly lower than that from controls. Moreover, average IL-10 production in BALF from the BCG/OVA group was higher than that from the OVA group, but the difference did not reach statistical significance. Further studies are needed to focus on whether it is possible that the anti-asthma effect of BCG is mediated by IL-10 produced by regulatory $\mathrm{T}$ cells.

RSV infection results in AHR and enhanced airway sensitization to allergens in the murine model $(22,33,34)$. Our results proved that mice infected with RSV before sensitization to OVA had higher AHR than non-RSV-infected mice, but other asthmatic parameters and the level of IFN- $\gamma$, IL-4, and IL-10 in BALF were not significantly different. In our 
previous study, we found that the concentration of IFN- $\gamma$ but not IL-4 and IL-10 increased in BALF on d 7 postinfection from mice infected with RSV as compared with noninfected controls (data not shown), which was consistent with other findings $(33,35)$ and could be explained as acute RSV infection resulting in a Th1-type cytokine response. However, in our present experimental system, augmentation of allergeninduced AHR after RSV infection could not be explained by a Th1/Th2 mechanism. Similar to our results, one report recently demonstrated that increased pulmonary expression of IL-4, IL-5, and IL-13 mRNA and aggravated alveolitis and hypertrophy of mucus-producing cells were observed only when OVA-sensitized mice were inoculated with RSV shortly before or during challenge with OVA (36). In this report, when RSV inoculation was performed before sensitization to OVA, Th2 cytokines mentioned above and Th1 cytokine IFN- $\gamma$ mRNA expression was similar to the ones without RSV inoculation. The time-dependent effect of RSV infection on OVA allergy may be determined by the OVA-induced cytokine milieu. So far, the precise role of RSV in the development of allergic asthma is not clear and might involve other mechanisms such as impairment in the inactivation of tachykinins, virus-induced nitric oxide production, and changes in neural control of the airways (37).

Despite decreased OVA-induced airway eosinophilia, AHR, and histologic inflammation after BCG vaccination in neonatal mice, the effects of BCG appeared to be reversed by subsequent RSV infection. This supports the hypothesis we proposed. It may also help explain why there are consistent results in animal models and controversial conclusions in humans from BCG anti-asthma research. Due to the sterile environment or lack of susceptibility to the pathogens they are exposed to, the experimental animals do not suffer from RSV infection or other virus infections closely linked to the development of asthma. In contrast to experimental animals, the situation is completely different in humans. Almost all children become infected with RSV during the first or second year of life, so that BCG's anti-asthma effect might not be obvious because of the intervening RSV infection. Certainly, some researchers argue that severe RSV lower respiratory tract infection in infancy is an independent risk factor for childhood asthma (38-40).

Serum OVA-specific IgE and cytokines of BALF in OVAsensitized/challenged mice were unaffected by BCG vaccination or/and RSV infection. These results are in agreement with the results from other studies $(30,33,36)$ and indicated that OVA-specific IgE, IFN- $\gamma$, IL-4, and IL-10 might not be responsible for changes of asthmatic inflammation and AHR caused by BCG and RSV interference in our mouse model.

Although our results imply that BCG vaccination in human neonates might not play a role of preventing childhood asthma because of inevitable RSV infection in infancy, the situation in human might be different from mice because of more complex life environment and a more diverse genetic background. The $\mathrm{BALB} / \mathrm{c}$ mice strain used in this study maybe more prone to abnormally pronounced inflammation due to RSV than other mouse strains. Further study is needed to determine whether the same results would be observed in other strains of mice.
In summary, neonatal BCG vaccination decreased asthmatic inflammation and AHR in OVA-sensitized/challenged mouse model whereas RSV infection before sensitization to OVA aggravated AHR. Hence, the anti-asthma effect of BCG could be reversed by RSV infection. The mechanism responsible for the impact of BCG and RSV on asthmatic inflammation and AHR in the mouse model will be studied further.

Acknowledgments. The authors thank Dr. Wayne M. Sullender, Department of Pediatrics, University of Alabama at Birmingham, and Dr. Helen Ka-wai Law, Department of Paediatrics and Adolescent, The University of Hong Kong, for proofreading the final manuscript.

\section{REFERENCES}

1. Weitzman M, Gortmaker SL, Sobol AM, Perrin JM 1992 Recent trends in the prevalence and severity of childhood asthma. JAMA 268:2673-2677

2. von Mutius E 2000 The environmental predictors of allergic disease. J Allergy Clin Immunol 105:9-19

3. Strachan DP 1989 Hay fever, hygiene, and household size. BMJ 299:1259-1260

4. Shirakawa T, Enomoto T, Shimazu S, Hopkin JM 1997 The inverse association between tuberculin responses and atopic disorder. Science 275:77-79

5. Erb KJ, Holloway JW, Sobeck A, Moll H, Le Gros, G 1998 Infection of mice with Mycobacterium bovis-Bacillus Calmette-Guerin (BCG) suppresses allergen-induced airway eosinophilia. J Exp Med 187:561-569

6. Herz U, Gerhold K, Gruber C, Braun A, Wahn U, Renz H, Paul K 1998 BCG infection suppresses allergic sensitization and development of increased airway reactivity in an animal model. J Allergy Clin Immunol 102:867-874

7. Hylkema MN, Timens W, Luinge M, Van Der Werf, N, Hoekstra MO 2002 The effect of bacillus Calmette-Guerin immunization depends on the genetic predisposition of Th2-type responsiveness. Am J Respir Cell Mol Biol 27:244-249

8. Major T, Wohlleben G, Reibetanz B, Erb KJ 2002 Application of heat killed Mycobacterium bovis-BCG into the lung inhibits the development of allergeninduced Th2 responses. Vaccine 20:1532-1540

9. Hattori H, Okano M, Yamamoto T, Yoshino T, Yamashita Y, Watanabe T, Satoskar AR, Harn DA, Nishizaki K 2002 Intranasal application of purified protein derivative suppresses the initiation but not the exacerbation of allergic rhinitis in mice. Clin Exp Allergy 32:951-959

10. Ozdemir C, Akkoc T, Bahceciler NN, Kucukercan D, Barlan IB, Basaran MM 2003 Impact of Mycobacterium vaccae immunization on lung histopathology in a murine model of chronic asthma. Clin Exp Allergy 33:266-270

11. Townley RG, Barlan IB, Patino C, Vichyanond P, Minervini MC, Simasathien T, Nettagul R, Bahceciler NN, Basdemir D, Akkoc T, Pongprueksa S, Hopp RJ 2004 The effect of BCG vaccine at birth on the development of atopy or allergic disease in young children. Ann Allergy Asthma Immunol 92:350-355

12. Choi IS, Koh YI 2003 Effects of BCG revaccination on asthma. Allergy 58:1114 1116

13. Marks GB, Ng K, Zhou J, Toelle BG, Xuan W, Belousova EG, Britton WJ 2003 The effect of neonatal BCG vaccination on atopy and asthma at age 7 to 14 years: an historical cohort study in a community with a very low prevalence of tuberculosis infection and a high prevalence of atopic disease. J Allergy Clin Immunol 111:541549

14. Nuhoglu Y, Nuhoglu C, Ozcay S 2003 The association between delayed type hypersensitivity reaction, Mycobacterium tuberculosis and atopy in asthmatic children. Allergol Immunopathol (Madr) 31:14-17

15. Schwarze J, Gelfand EW 2002 Respiratory viral infection as promoters of allergic sensitization and asthma in animal models. Eur Respir J 19:341-349

16. Sigurs N, Bjarnason R, Sigurbergsson, F, Kjellman B 2000 Respiratory syncitial virus bronchiolitis in infancy is an important risk factor for asthma and allergy at age 7. Am J Respir Crit Care Med. 161:1501-1507

17. Stein RT, Sherrill D, Morgan WJ, Holberg CJ, Halonen M, Taussig LM, Wright AL, Martinez FD 1999 Respiratory syncytial virus in early life and risk of wheeze and allergy by age 13 years. Lancet 354:541-545

18. Hall CB 2001 Respiratory syncytial virus and parainfluenza virus. N Engl J Med 344:1917-1928

19. Graham BS, Bunton LA, Wright PF, Karzon DT 1991 Role of T lymphocyte subsets in the pathogenesis of primary infection and rechallenge with respiratory syncytial virus in mice. J Clin Invest 88:1026-1033

20. Oh SW, Pae CI, Lee DK, Jones F, Chiang GK, Kim HO, Moon SH, Cao B, Ogbu C, Jeong KW, Kozu G, Nakanishi H, Kahn M, Chi EY, Henderson WR Jr 2002 Tryptase inhibition blocks airway inflammation in a mouse asthma model. J Immunol 168:1992-2000

21. Renz H, Bradley K, Larsen GL, McCall C, Gelfand EW 1993 Comparison of the allergenicity of ovalbumin and ovalbumin peptide 323-339. Differential expansion of V beta-expressing T cell populations. J Immunol 151:7206-7213

22. Peebles RS Jr, Sheller JR, Collins RD, Jarzecka AK, Mitchell DB, Parker RA, Graham BS 2001 Respiratory syncytial virus infection does not increase allergen- 
induced type 2 cytokine production, yet increases airway hyperresponsiveness in mice. J Med Virol 63:178-188

23. Hopfenspirger MT, Agrawal DK 2002 Airway hyperresponsiveness, late allergic response, and eosinophilia are reversed with mycobacterial antigens in ovalbuminpresensitized mice. J Immunol 168:2516-2522

24. Strachan DP 1989 Hay fever, hygiene, and household size. BMJ 299:1259-1260

25. Liu AH, Szefler SJ 2003 Advances in childhood asthma: hygiene hypothesis, natural history, and management. J Allergy Clin Immunol 111:S785-S792

26. Liu AH, Murphy JR 2003 Hygiene hypothesis: fact or fiction? J Allergy Clin Immunol 111:471-478

27. Umetsu DT, McIntire JJ, Akbari O, Macaubas C, DeKruyff RH 2002 Asthma: an epidemic of dysregulated immunity. Nat Immunol 3:715-720

28. Yazdanbakhsh M, Kremsner PG, van Ree, R 2002 Allergy, parasites, and the hygiene hypothesis. Science 296:490-494

29. Nahori MA, Lagranderie M, Lefort J, Thouron F, Joseph D, Winter N, Gicquel B, Lapae Silva JR, Vargaftig BB 2001 Effects of Mycobacterium bovis BCG on the development of allergic inflammation and bronchial hyperresponsiveness in hyperIgE BP2 mice vaccinated as newborns. Vaccine 19:1484-1495

30. Bakir M, Tukenmez F, Bahceciler NN, Barlan IB, Basaran MM 2000 Heat-killed Mycobacterium bovis-Bacillus Calmette Guerin-suppressed total serum IgE response in ovalbumin-sensitized newborn mice. J Asthma 37:329-334

31. Zuany-Amorim C, Sawicka E, Manlius C, Moine A, Brunet LR, Kemeny DM, Bowen G, Rook G, Walker C 2002 Suppression of airway eosinophilia by killed Mycobacterium vaccae-induced allergen-specific regulatory T-cells. Nat Med 8:625-629
32. Liu E, Law HK, Lau YL 2003 BCG promotes cord blood monocyte-derived dendritic cell maturation with nuclear Rel-B up-regulation and cytosolic I kappa B alpha and beta degradation. Pediatr Res 54:105-112

33. Schwarze J, Hamelmann E, Bradley KL, Takeda K, Gelfand EW 1997 Respiratory syncytial virus infection results in airway hyperresponsiveness and enhanced airway sensitization to allergen. J Clin Invest 100:226-233

34. Peebles RS Jr, Sheller JR, Johnson JE, Mitchell DB, Graham BS 1999 Respiratory syncytial virus infection prolongs methacholine-induced airway hyperresponsiveness in ovalbumin-sensitized mice. J Med Virol 57:186-192

35. Jafir HS, Chávez-Bueno S, Mejías A, Gómez AM, Rios AM, Nassi SS, Yusuf M Kapur P, Hardy RD, Hatfield J, Rogers BB, Kisher K, Ramilo O 2004 Respiratory syncytial virus induces pneumonia, cytokine response, airway obstruction, and chronic inflammatory infiltrates associated with long-term airway hyperresponsiveness in mice. J Infect Dis 189:1856-1865

36. Barends M, Van Oosten M, De Rond CG, Dormans JA, Osterhaus AD, Neijens HJ, Kimman TG 2004 Timing of infection and prior immunization with respiratory syncytial virus (RSV) in RSV-enhanced allergic inflammation. J Infect Dis 189:1866-1872

37. Jacoby DB 2002 Virus-induced asthma attacks. JAMA 287:755-761

38. Schauer U, Hoffjan S, Bittscheidt J, Kochling A, Hemmis S, Bongartz S, Stephan V 2002 RSV bronchiolitis and risk of wheeze and allergic sensitisation in the first year of life. Eur Respir J 20:1277-1283

39. Sigurs N 2002 A cohort of children hospitalised with acute RSV bronchiolitis impact on later respiratory disease. Paediatr Respir Rev 3:177-183

40. Oddy WH, de Klerk NH, Sly PD, Holt PG 2002 The effects of respiratory infections, atopy, and breastfeeding on childhood asthma. Eur Respir J 19:899-905 